\title{
A governança atual dos sistemas educativos e a regressão do direito à educação
}

\author{
Eliza Bartolozzi Ferreira* \\ Maria Alice de Miranda Aranda** \\ Rodrigo da Silva Pereira***
}

A Rede de Estudos e Pesquisas em Planejamento e Gestão Educacional (REPLAG) vem apresentar uma proposta de dossiê como forma de compartilhar os resultados das pesquisas desenvolvidas pelo grupo no campo da educação. A Replag foi constituída no ano de 2013 com o objetivo de reunir pesquisadores de todo o país e da América Latina voltados aos estudos do planejamento e da gestão de sistemas educacionais em âmbito internacional, nacional e/ou local. Os estudos nesse campo científico se apresentam cada vez com maiores desafios tendo em vista os ajustes fiscais adotados pelos entes da federação brasileira, sobretudo, após a promulgação da legislação atual que estabelece um teto nos investimentos sociais que ameaça o caráter público e gratuito da educação escolar. Ademais, o projeto cultural conservador em curso no Brasil e em outros países vem disputar uma agenda política-pedagógica de regressão dos direitos humanos e do exercício do trabalho docente. O recrudescimento do projeto neoliberal de sociedade exige juntar esforços de pesquisadores e de trabalhadores docentes na defesa do direito à educação pública, laica, gratuita e emancipadora.

Por isso o debate sobre as novas e velhas formas de regulação da gestão dos sistemas educacionais se apresenta relevante nesse atual contexto de recrudescimento das forças conservadoras e ultraliberais. Desde a década de 1990, o campo da política educacional latino-americana e europeia vem problematizando as formas de regulação da educação pública que se apresentam de cariz gerencialista, tal como funciona o mercado.

* Universidade Federal do Espírito Santo. Vitória, Espírito Santo, Brasil. E-mail: eliza. bartolozzi@gmail.com. https://orcid.org/0000-0002-4100-9875.

** Universidade Federal da Grande Dourados. Dourados, Mato Grosso do Sul, Brasil. E-mail: mariaaranda@ufgd.edu.br. http://orcid.org/0000-0003-2561-7579.

**** Universidade Federal da Bahia. Salvador, Bahia, Brasil. E-mail: rodrigosilvapereira@ ufba.br. https://orcid.org/0000-0003-0371-3789. 
Por isso, a literatura do campo da política educacional centra suas análises buscando compreender a governança atual dos sistemas educativos no contexto da globalização. O termo governança é definido como a forma de governar baseada no equilíbrio entre o Estado, a sociedade civil e o mercado, ao nível local, nacional e internacional (BARROSO, 2018). Nesse cenário, são observadas várias formas de regulação, novas e velhas, que convivem de maneira a concretizar a lógica da nova gestão pública (NGP) que visa promover uma gestão educacional pautada em resultados tangíveis no mesmo compasso em que privilegia a descentralização ou, muitas vezes, a fragmentação dos serviços públicos em unidades de gestão independentes.

Nesse sentido, os textos publicados neste dossiê procuram analisar as formas de regulação das políticas educacionais levadas a cabo no Brasil, complementando com as experiências da França e da Argentina como exemplos do que vem ocorrendo na Europa e na América Latina. A perspectiva aqui adotada sobre a regulação se assenta no trabalho de Barroso (2005; 2018) e Maroy (2011), que entendem que a gestão das políticas educacionais deve ser pensada em termos de ação pública e não mais como uma obra linear da administração. Os estudos das políticas públicas devem focar os conflitos e os arranjos construídos por uma diversidade de atores que participam de um determinado processo nada linear, mas composto de uma multiplicidade de ações estatal, pública e privada. Dessa forma, o termo que retrata melhor a gestão das políticas educacionais é a multirregulação, pois essas políticas ocorrem em variados níveis - transnacional, nacional, local - onde intervém uma variedade de atores (públicos e/ou privados) no contexto da governança.

Considerada como um processo dinâmico, a regulação é portadora tanto da ordem quanto de novas tensões (MAROY, 2011). Os trabalhos aqui apresentados são resultados de pesquisas que revelam a convivência de velhas e novas formas de regulação da gestão das políticas educacionais.

O primeiro artigo produzido pelas professoras Elisangela Alves da Silva Scaff, Eliza Bartolozzi Ferreira e Marília Fonseca é fruto de uma pesquisa empírica dedicada ao tema da gestão e do planejamento educacional. O texto analisa a política educacional brasileira a partir das últimas décadas do século XX, cuja regulação, inicialmente centrada no Estado, passou por transformações agudas já na década de 1990 quando a regulação transnacional é levada a cabo na gestão da educação brasileira. O texto examina as formas de configuração da gestão e do planejamento educacional após o período da ditadura militar até o governo Lula da Silva, quando as formas de regulação nacional e local concorrem para desenvolver uma experiência 
democrática de planejamento educacional que apresentam diversos arranjos organizacionais.

O artigo escrito por Maria Aranda Alice de Miranda e Evally Solaine de Souza Rodrigues consiste em um balanço sobre a produção do conhecimento referente ao monitoramento e avaliação dos planos decenais de educação, no período de 2001 a 2017, compreendidos como Plano Nacional de Educação (PNE), Plano Estadual de Educação (PEE) e Plano Municipal de Educação (PME). As autoras fazem uma pesquisa bibliográfica e exploratória de natureza quali-quantitativa, com significativa contribuição para o campo que se apresenta ainda em formação. A partir desse esforço bibliográfico, o texto revela a necessidade de estudos sobre as formas de regulação nacional e local ocorridas no Brasil no exercício legal dos planos educacionais.

O terceiro artigo trata-se de um estudo desenvolvido por Jorge Gorostiaga, da Argentina. O objetivo do texto é analisar como e em que medida a retórica das organizações multilaterais se alinha com a promoção de modelos de regulação pós-burocrática da educação no contexto latino-americano. O autor analisa documentos patrocinados por agências multilaterais da região, publicados entre 2012 e 2018, de modo a identificar os temas e abordagens dominantes, mas também as contradições, variações, ênfases diferentes e abordagens alternativas.

O artigo de Maira de Araújo Mamede, da Université Paris-Est Créteil, apresenta um estudo a partir da experiência francesa sobre as características do seu corpo docente. Especificamente, o estudo aborda as políticas de formação e de entrada no ofício docente, com destaque para sua heterogeneidade em um país de características políticas centralizadoras. O texto analisa dados da realidade das condições dos trabalhadores docentes que são interessantes para os estudos comparativos entre países que, não obstante suas diferenças, estão situados em uma agenda global da educação cujo processo dinâmico de regulação imprime velhos conflitos e instala novos arranjos profissionais.

A produção coletiva de Maura da Silva Miranda, Maria Couto Cunha e Rodrigo da Silva Pereira apresenta resultados de pesquisa construídos a partir da análise de documentos e entrevistas semiestruturadas com o objetivo de investigar os arranjos institucionais de gestão territorial da educação por meio dos Consórcios Públicos (CP) e Arranjos de Desenvolvimento da Educação (ADE) em parceria público-privado, demonstrando as iniciativas em curso no estado da Bahia com os Consórcios Públicos sob a iniciativa governamental. Os resultados preliminares sinalizam as formas de regulação centradas no crescimento de parcerias público-privadas no âmbito dos preceitos da Nova Gestão Pública que sustentam a conformação desses arranjos.

A partir de pesquisa desenvolvida na rede estadual de Goiás, a professora Luciana Rosa Marques apresenta dados de pesquisa realizada a 
partir de entrevistas com os dirigentes das escolas de maior e menor Índice de Desenvolvimento da Educação Básica (IDEB) do estado, sindicato dos profissionais de educação e secretaria de educação. O estudo busca verificar quais as repercussões da Nova Gestão Pública (NGP) na gestão da educação na rede pública estadual de Goiás, estado que se destaca pelos bons resultados alcançados em avaliações de larga escala. A autora observa a convivência de duas lógicas: a NGP e a gestão democrática estão presentes no discurso dos participantes da pesquisa.

O artigo de Marilda de Oliveira Costa e Cassia Domiciano traz reflexões críticas sobre a conjuntura política nacional e do estado de Mato Grosso. Especificamente, as autoras analisam as alterações legislativas da gestão democrática no sistema de ensino de Mato Grosso e na escola pública para a formação de sujeitos democráticos e participativos. Suas análises levam a conclusão de que vivemos uma pós-democracia gestionária, sob influência da Nova Gestão Pública (NPM) e das suas orientações gerencialistas em substituição à gestão democrática e suas potencialidades na construção da escola democrática.

Por fim, o artigo de Maria José Pires Barros Cardozo e Maria Lília Imbiriba Sousa Colares se propõe a discutir os Sistemas Municipais de Educação (SME) na Mesorregião Oeste Maranhense, em especial o princípio da gestão democrática nos municípios que institucionalizaram os seus SME. Para tanto, as autoras abrangem aspectos e questões teóricas e legais que fundamentam a concepção de sistema educacional e a gestão democrática como premissas que orientam a criação dos SME. No contexto atual, caracterizado pela ênfase na regulação local (municipal), este trabalho traz importante contribuição para este Dossiê porque acentua o papel fundamental do SME e do Conselho Municipal da Educação (CME) para o processo de planejamento municipal, uma vez que o CME poderá ser o mobilizador do processo de diálogo entre a sociedade civil e a política e, em articulação com os fóruns municipais e outros instrumentos de acompanhamento e controle social da educação, ambos poderão contribuir para a elaboração, acompanhamento e avaliação do Plano Municipal de Educação (PME) e, por consequência, possibilitar o exercício da gestão democrática.

\section{REFERÊNCIAS}

BARROSO, J. O Estado, a educação e a regulação das políticas públicas. In: Educação e Sociedade. Campinas: CEDES, v. 26, n. 92, 2005. p. 725-751. 
BARROSO, J. A transversalidade das regulações em educação: modelo de análise para o estudo das políticas educativas em Portugal. In: Educação e Sociedade. Campinas: CEDES, v. 39, n. 145, 2018. p. 1075-1097.

MAROY, C. Em direção a uma regulação pós-burocrática dos sistemas de ensino na Europa? In: OLIVEIRA, D. A.; DUARTE, A. M. C. (Orgs.). Políticas públicas e educação. Belo Horizonte: Editora Fino Traço, 2011. p. 19-46.

Texto recebido em 20/11/2019.

Texto aprovado em 01/12/2019. 